\title{
Effect of teachers' Psychological Ownership on their Professional morality: The Mediating Effect of Organizational Identification
}

\author{
Shan $\mathrm{Hu}^{\mathrm{a}}$, Huiyong $\mathrm{Fan}^{\mathrm{b}}$ \\ School of Education and Sports, Bohai University, Jinzhou, 121013, China \\ a349645000@qq.com, b570950454@qq.com
}

\begin{abstract}
Keywords: primary and middle school teacher; psychological ownership; professional commitment; organizational identification; professional morality; mechanism
\end{abstract}

Keywords. Teachers' professional morality has become the focus of the current education reform and teachers' team construction, the article from the perspective of organizational citizenship behavior theory proposed teacher psychological ownership, professional commitment, and organizational identification can predict their professional moral behavior. In order to study the mechanism of teacher psychological ownership have an impact on professional morality of teachers, especially research professional commitment and organizational identification in which intermediary role, for 208 primary and secondary school teachers conducted a survey. The results showed that: the teachers' psychological ownership is significantly positive correlation with professional commitment, organizational identification, and teachers' professional morality, and organizational identification plays a significant intermediary role between teachers' psychological ownership and professional morality, mediating effect of occupational commitment is not significant.

\section{Introduction}

China has more than ten million primary and secondary school teachers, shouldering the sacred mission of fostering and educating the more than 200 million students. Teachers' identity determines the high requirements of the state and society for teachers' professional morality. Teachers' professional morality (teachers' morality), is the sum of the relatively stable moral values, behavior norms and moral qualities that are formed by the teachers in the educational activities. As a core component of teacher quality, teachers 'professional morality has become the focus of the current education reform and teachers' team construction [1]. Although teachers' morality is so important, but most of the existing morality research is the theoretical analysis, there is little empirical research; in empirical research, the research on the status of teachers' morality is more, and on the education of teachers' morality or the intervention is less. Usually about the teacher's moral intervention method: one conducted knowledge teaching, such as training on morality aspects and lectures; second is carries on the typical deed report. But the effects of usual teachers' morality intervention method are limited, and can expand the new method of teachers' morality intervention?

The organizational behavior research of domestic and foreign shows that [2-4] the individual in the organization can make a behavior which is beneficial to the interests of the organization under certain conditions, which includes professional moral behavior. This is to solve the problem of teachers' professional morality upgrade provides inspiration. So, is teacher's organizational citizenship behavior able to predict its professional moral behavior? Some researchers have made clear that "organizational citizenship behavior is beneficial organizational role behavior made by a member of the voluntary, in perfecting individual value, to achieve organizational goals, to expand on the meaning of social production reflects the promotion of professional morality of the organization's members [5]." From the perspective of educational organization behavior, in order to promote moral growth of teachers, we must stimulate the moral behavior of teachers. How to motivate teachers moral behavior, it is an important issue that school administrators have to face and thinking. On the connotation and characteristics, organizational citizenship behavior and moral 
behavior has a great similarity. This revelation: from the perspective of organizational citizenship behavior theory to study the moral behavior of teachers [6].

Organizational citizenship behavior refers to voluntary behavior of the individual, these behavior have not been direct or clear return by formally reward system in the organization, which behavior to enhance the effective functioning of the organization as a whole. Existing organizational behavior variables include: psychological ownership, professional commitment, organizational identification.

Psychological ownership is proposed by Pierce and his colleagues in the study of employee stock ownership plan, which means that the individual thinks that the target belongs to the state of its own feeling", that it is "my" or "your". It contains both emotional and cognitive factors. Psychological ownership emotion can stimulate the positive attitude of the target entity; in addition, its ownership will inspire a sense of responsibility, these responsibilities include organization investment beyond the time and energy, protection and care organization, willing to for the organization to assume certain risks and to make sacrifices.

You Lirong and Li Xia pointed out that teachers' professional commitment is a three-factor structure, which included emotional commitment, continued commitment and normative commitment. The so-called emotional commitment that is like current occupation, and the profession in line with their career aspirations, interests and do not want to leave their current job; continuance commitment refers to consider to leave current career would lead to lost profits or difficult to find the ideal profession rather than leaving the current occupation; normative commitment refers to the accepted norms of social ethics rather than leave current occupation.

Organizational identification is a kind of self perceived of the employees' identity and emotional attribution of staff for organization [7], the performance of members of the organization in terms of psychological and behavioral consistency with which they joined the organization.

Empirical research has found that psychological ownership and organizational citizenship behavior positively correlated [8]. The emotional commitment and normative commitment is the intermediary variable of employee psychological ownership and organizational citizenship behavior, but emotional commitment plays an intermediary role completely, and normative commitment plays the partial intermediary role. Another study noted that psychological ownership can predict organizational citizenship behavior, and it is primarily by the intermediary role of the emotional commitment and organizational identification to impact on organizational citizenship behavior [9].

According to these studies, the teachers' psychological ownership, professional commitment and organizational identification have a positive predictive role on the behavior of teachers' professional morality. Specifically, it is assumed, teacher' psychological ownership through professional commitment, organizational identification affect teachers' professional moral behavior. H1, teacher psychological ownership forward prediction teachers professional moral level, teacher psychological ownership to influence professional moral behavior of teachers through professional commitment and organization identification, namely professional commitment and organizational identification plays an mediating variables role between psychological ownership and professional moral behavior of teachers; H2a, professional commitment plays an mediating variables role between teachers' psychological ownership and teachers' moral behavior; H2b, organizational identification plays an mediating variables role between teachers' psychological ownership and teachers' moral behavior. in-depth interview is an unstructured, direct, personal access, in the course of the visit, through in-depth interviews with a respondent to reveal the potential motives of a problem, beliefs, attitudes and feelings; reliability analysis method is analyzed consistency degree of obtained results that using the same method when repeated measurements of the same object, reliability index are expressed by the correlation coefficient; statistical analysis method is to use mathematical methods, establish the mathematical model, survey obtained a variety of data and information conducted mathematical statistics and analysis, the formation of quantitative conclusions, is a scientific evaluation methods; case analysis method is a method that truthfully and accurately record case occurrence, development, change process and targeted analysis, research. 


\section{Research Tools}

Teacher psychological ownership scale [10], a total of 12 projects, the internal consistency coefficient of the scale was 0.86; the measurement of professional commitment using teachers' professional commitment questionnaire prepared by Li Xia, a total of 16 projects, the consistency coefficient and homogeneous reliability of the scale was more than 0.74 ; teachers' organizations identity measured using teachers' organizations identification scale prepared by Li Yongxin and others, a total of 6 projects. The internal consistency coefficient of the scale was 0.82 . The above three questionnaires are used Likert 5 points scale to record score, 1 represents very not meet, 2 represents more not meet, 3 represents poorly defined, 4 represents more meet, 5 represents very meet. Teachers' professional morality measured using the self-made teachers' professional morality questionnaire. The questionnaire reference to the 2008 revision of the "Teachers' professional ethics in primary and middle school", including the moral values and moral behavior of two dimensions, a total of 14 projects, and the internal consistency coefficient of the questionnaire was 0.88 .

The use of SPSS17.0 carries on data management and analysis. SPSS is the first graphical menu-driven interface statistical software in the world, the most prominent feature is the user interface is extremely friendly and output beautiful appearance. It almost all functions in a uniform, standardized interface to show up, use the Windows window way to show functions of the various methods of data management and analysis, dialog demonstrate various functions options. As long as the user to master a certain Windows operation skills, proficient in statistical analysis principle, you can use the software for a specific scientific research work.

\section{Research Result}

From Liaoning province, Shenyang, Dalian, Anshan, Fushun, Benxi, Dandong, Jinzhou, Yingkou, Fuxin, Liaoyang, Tieling, Chaoyang, Panjin, Huludao, a total of 14 city, a total of 228 primary and middle school backbone teachers, and finally, the real effective questionnaire was 208 parts (efficiency with 91.2\%). The results are as follows:

(1) Descriptive statistics and correlation analysis. In order to verify the hypothesis 1 , 2, this section uses correlation analysis, respectively, to study whether there is a significant correlation between any two of the four variables, there is a certain correlation between the only variable to be mediating effect test. Sampling Samples of psychological ownership, professional commitment, organizational identity, professional morality and other variables as well as the various dimensions of the variables descriptive statistics were done and correlation analysis, the results are shown in Table 1, psychological ownership, professional commitment, organizational identity, professional morality are pairwise significant correlation, the results indicated that the professional commitment and organizational identity may have an intermediary role between the psychological ownership and professional morality.

Table 1. Descriptive statistics and correlation analysis results of variable

\begin{tabular}{c|c|c|c|c|c|c}
\hline & $\begin{array}{c}\text { Mean } \\
\text { value }\end{array}$ & $\begin{array}{c}\text { Standard } \\
\text { deviation }\end{array}$ & $\begin{array}{c}\text { Psychological } \\
\text { ownership }\end{array}$ & $\begin{array}{c}\text { Professional } \\
\text { commitment }\end{array}$ & $\begin{array}{c}\text { Organizational } \\
\text { identification }\end{array}$ & $\begin{array}{c}\text { Professional } \\
\text { ethics }\end{array}$ \\
\hline $\begin{array}{c}\text { Psychological } \\
\text { ownership }\end{array}$ & 4.332 & 0.530 & 1.000 & & \\
\hline $\begin{array}{c}\text { Professional } \\
\text { commitment }\end{array}$ & 3.953 & 0.540 & 0.668 & 1.000 & & \\
\hline $\begin{array}{c}\text { Organizational } \\
\text { identification }\end{array}$ & 4.537 & 0.544 & 0.716 & 0.611 & 1.000 & \\
\hline $\begin{array}{c}\text { Professional } \\
\text { ethics }\end{array}$ & 0.862 & 0.125 & 0.415 & 0.293 & 0.366 & 1.000 \\
\hline
\end{tabular}

(2) The mediating effect analysis of teachers' professional commitment. The results are shown in table 2.

Psychological ownership significantly forward influence the professional morality (nonstandard 
regression coefficient was $0.415, p<0.000$ ), which was verified by hypothesis 1 . Since inspected $\mathrm{y}$ in turn for $\mathrm{m}$ regression coefficient is not significant $(t=0.341, p>0.05)$, according to the proposed test program, you need to do Sobel test, the test statistic is:

$$
z=\hat{a} \hat{b} / \sqrt{\hat{a}^{2} s_{b}^{2}+\hat{b}^{2} s_{a}^{2}}
$$

In this $\hat{a}=0.668, S_{a}=0.053, \hat{b}=0.029, S_{b}=0.020$.

Calculated $z=1.44, p>0.05$. So mediating effect of professional commitment was not significant, $\mathrm{H} 2 \mathrm{a}$ is rejected

It is assumed that the psychological ownership of a teacher affects the organizational identification, and the organizational identification can affect the professional morality of teachers.

Table 2. Sequence test on mediation effect of professional commitment

\begin{tabular}{c|c|c}
\hline & Standardized regression equation & \multicolumn{2}{|c}{ Regression coefficient test } \\
\hline Step 1 & $y=0.415 x$ & $S E=0.015 \quad t=6.551$ \\
\hline Step 2 & $m=0.668 x$ & $S E=0.053 \quad t=12.883$ \\
\hline Step 3 & $y=0.029 m$ & $S E=0.020 \quad t=0.341$ \\
\hline & $+0.396 x$ & $S E=0.020 \quad t=4.637$ \\
\hline
\end{tabular}

(3) The mediating effect analysis of teachers' organizational identification. The results are shown in table 3.

Table 3. Sequence test on mediation effect of organizational identification

\begin{tabular}{c|c|cc}
\hline & Standardized regression equation & \multicolumn{2}{|c}{ Regression coefficient test } \\
\hline Step 1 & $y=0.415 x$ & \multicolumn{2}{|c}{$S E=0.015 \quad t=6.551$} \\
\hline Step 2 & $S E=0.050 \quad t=14.713$ \\
\hline Step 3 & $y=0.141 \mathrm{v}$ & $S E=0.021 \quad t=1.554$ \\
\hline & $+0.315 x$ & $S E=0.021 \quad t=3.478$ \\
\hline
\end{tabular}

Since inspected $\mathrm{y}$ in turn for $\mathrm{m}$ regression coefficient is not significant $(t=1.554, p>0.05)$, according to the proposed test program, you need to do Sobel test, the test statistic is still using the formula (1).

In this $\hat{a}=0.716, S_{a}=0.050, \hat{b}=0.141, S_{b}=0.021$.

Calculated $z=6.08, \quad p>0.05$. So mediating effect of organizational identification was significant, $\mathrm{H} 2 \mathrm{~b}$ is verified.

According to the above analysis, the part of the intermediary role model of the organizational identification between the teachers' psychological ownership and teachers' professional morality is shown in Fig. 1.

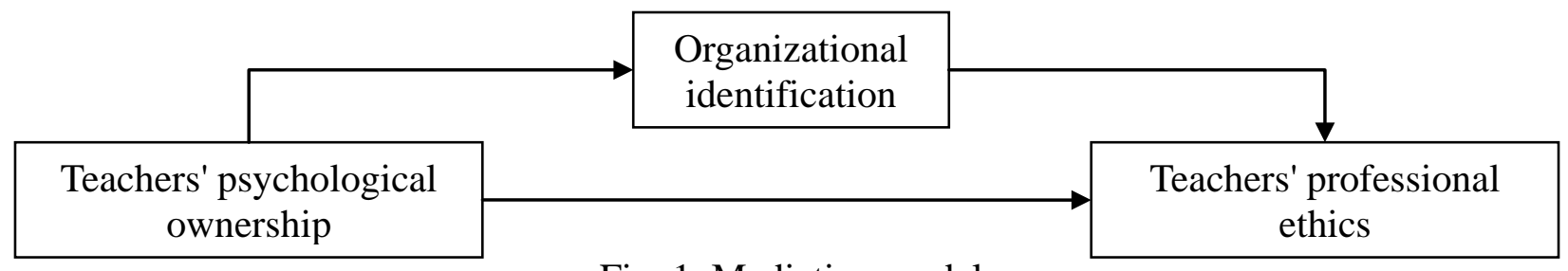

Fig. 1. Mediation model 


\section{Conclusion}

This study firstly verified the effect mechanism of the teacher's psychological ownership on the teachers' professional morality: teacher' psychological ownership not only has a direct impact on the professional morality of teachers, but also to influence the professional morality by the organization identification. Specifically, organizational identification plays an intermediary role in the relationship between teachers' psychological ownership and teachers' professional morality.

Most of the existing research supports the forward prediction of psychological ownership on organizational citizenship behavior. Consistent with these findings, this study also showed that psychological ownership on moral behavior has a significant forward prediction. Further, professional commitment and organizational identity may be the result variable of psychological ownership, are also mediating variables between psychological ownership of teachers and teachers' professional ethics, but professional commitment play a partial mediating role, and organizational identification play a completely mediating role, that psychological ownership is thus indirectly affecting teachers' professional moral behavior by influencing teachers' organizations identification. This indicates that under the influence of the traditional culture of collectivism, the teacher's attribution needs strong, when a teacher has a psychological ownership of the school, they will put themselves in touch with the school together, the school as their own "home", to identify the schools. Therefore, the teacher' psychological ownership affect organizational identity of teachers; and when teachers produce more intense sense of belonging and identity for school, they will volunteer for the school to work harder, thus showing more professional moral behavior.

This study suggests that the new ways and means to upgrade teachers' professional moral behavior. In addition to the traditional teachers' professional morality aspects related to systematic training, lectures, reports, courses, teachers can also be used to enhance professional moral behavior by improving teachers' psychological ownership and organizational identity.

\section{References}

[1] J. L. Shen, J. Z. Zhao, "The reality of primary and secondary school teachers' professional ethics thinking," Journal of Beijing normal university (social science edition), vol. 40, no. 1, pp. 48-55, 2006.

[2] Ronit Boglera, Anit Somech, "Influence of Teacher Empowerment on Teachers Organizational Commitment," Teaching and Teacher Education, vol. 20, no. 1, pp. 277-289, 2004.

[3] Izhar Oplatka, "Going Beyond Role Expectations: Towardan Understanding of the Determinants and Components of Teacher Organizational Citizenship Behavior," Educational Administration Quarterly, vol. 42, no. 1, pp. 385-423, 2006.

[4] G. H. Zhou, G. M. Li, "Who is a good teacher in College, An empirical study on the characteristics of College Teachers' organizational citizenship behavior," Teacher education research, vol. 21, no. 4, pp. 71-75, 2009.

[5] G. Z. Liu, L. Y. Tao, "Ethical review of organizational citizenship behavior," Administration of China, vol. 33, no. 1, pp. 79-82, 2012.

[6] Y. X. Yang, "Teachers' moral behavior and moral development: from the perspective of organizational citizenship behavior," Education Development Research, vol. 35, no. 24, pp. 42-47, 2012.

[7] J. Chen, "How psychological ownership affects the behavior of the employees' organizational citizenship behavior, organizational identification and organizational commitment," Business economics and management, vol. 22, no. 7, pp. 24-30, 2011. 
[8] Michael P, O'driscol, Jon L Pierce, Ann-Marie Coghlan, "The Psychology of Ownership: Work Environment Structure," Group Organization Management, vol. 31, no. 1, pp. 388-416, 2006.

[9] F. Liu, H. Wang, "Relationship between organizational psychological ownership and work attitude, behavior and results," Soft science, vol. 24, no. 9, pp. 124-128, 2010.

[10] Y. D. You, J. W. Long, "The establishment and application of teacher psychological ownership scale," Teacher education research, vol. 23, no. 3, pp. 51-55, 2011. 